\title{
Osteología Comparada del Esqueleto Caudal de Achirus lineatus y Achirus mazatlanus (Pleuronectiformes: Achiridae)
}

\author{
Comparative Osteology of the Caudal Skeleton of Achirus lineatus \\ and Achirus mazatlanus (Pleuronectiformes: Achiridae) \\ "Gracian-Negrete Jatziry Marlene; *Adrián Felipe González-Acosta; **Mónica González-Isáis; \\ "José Luis Ortiz-Galindo \& ** Luis Fernando Del Moral-Flores
}

\begin{abstract}
GRACIAN-NEGRETE, J. M.; GONZÁLEZ-ACOSTA, A. F.; GONZÁLEZ-ISÁIS. M.; ORTIZ-GALINDO, J. L. \& DEL MORAL-FLORES, L. F. Osteología comparada del esqueleto caudal de Achirus lineatus y Achirus mazatlanus (Pleuronectiformes: Achiridae). Int. J. Morphol., 30(2):705-708, 2012.
\end{abstract}

RESUMEN: El esqueleto caudal constituye una importante herramienta para evaluar las relaciones ancestro-descendencia de los peces teleósteos. Por tal motivo, se realizó un análisis osteológico comparativo de dicha estructura, a partir de ejemplares de las especies Achirus lineatus (Linnaeus, 1758) y A. mazatlanus (Steindachner, 1869), obtenidos de colecciones científicas de referencia y recolectados in situ en Veracruz y Baja California Sur (México). Los organismos fueron identificados con claves taxonómicas especializadas y procesados mediante la técnica de aclaración y tinción diferencial, para evaluar las posibles similitudes o diferencias en las estructuras que componen al complejo caudal. Achirus lineatus y A. mazatlanus se caracterizan por la presencia de una fórmula caudal compuesta por 1 epural + 5 hipurales +1 parahipural, además de una espina neural y dos espinas hemales; así como por la presencia de 16 radios principales y la ausencia de los radios procurrentes y el uroneural. Asimismo, se observo que en la especie A. lineatus, los hipurales se encuentran más cercanos uno del otro; sin embargo, en lo general, no se aprecio una clara diferencia en los elementos que componen la aleta caudal de las especies bajo estudio. Por consiguiente A. lineatus y A. mazatlanus son consideradas como especies fraternas.

PALABRAS CLAVE: Pleuronectiformes; Achiridae; Achirus; Esqueleto caudal; Aclaración y tinción diferencial; osteología comparada.

\section{INTRODUCCIÓN}

Los peces planos se caracterizan por presentar la mayor especialización anatómica conocida dentro del grupo de los vertebrados, la cual se manifiesta en la asimetría corporal de sus formas adultas, ocasionada por la migración de uno de los ojos durante su desarrollo larvario (Friedman, 2008; Janvier, 2008).

De modo particular, los peces de la Familia Achiridae se caracterizan por presentar ambos ojos de lado derecho del cuerpo; además, por su distribución en ambientes marino-estuarinos y dulceacuícolas en ambas costas de América. Dentro de esta familia se encuentran las especies Achirus lineatus cuya distribución va desde Florida (EUA) hasta Uruguay incluyendo el Golfo de México y A. mazatlanus que se distribuye desde la costa occidental de la Península de Baja California Sur incluyendo el Golfo de California, hasta Perú (Castro-Aguirre et al., 1999). Aunque dichas es- pecies se encuentran separadas geográficamente, se ha observado que comparten características muy semejantes como la coloración y el número de radios de las aletas dorsal, anal y pectoral (Gracian-Negrete, 2009).

El estudio del esqueleto caudal ha sido abordado en diferentes grupos de peces, lo que ha demostrado su valor diagnóstico para la separación entre familias, géneros o bien a nivel de especie (Eastman, 1980; Tucker, 1982; Hilton \& Johnson, 2007); además de su importancia para el conocimiento del grado evolutivo de las mismas, ya que representa una simplificación progresiva del origen tan complejo que caracteriza a numerosos huesos independientes tal como lo es la fusión de hipurales (Gosline, 1961) que se da al inicio de su desarrollo en los peces planos (Balart, 1985). Esta situación le confiere a dicha estructura, un alto valor taxonómico y filogenético. De manera general, la composi-

\footnotetext{
* Centro Interdisciplinario de Ciencias Marinas- IPN. Ave. Instituto Politécnico Nacional s/n. Col Playa Palo de Santa Rita. La Paz, BSC, México.

** Facultad de Estudios Superiores Iztacala-UNAM. Ave. de Los Barrios \# 1. Tlalnepantla, Edo. México.
} 
ción estructural del esqueleto caudal de los Pleuronectiformes ha sido descrita a partir del análisis en varias de sus especies, a través de estudios del desarrollo en periodos de larva a juvenil (Tucker; Balart; Ortiz-Galindo et al., 1990). En dichos estudios ha sido posible observar un amplio margen de variación estructural entre las especies, en aspectos tales como la reducción o pérdida de los uroneurales, así como la fusión de los huesos hipurales (e.g., Etropus) y del hueso epural con el hipural 5, aspectos que son característicos de algunos Pleuronectiformes. En el presente estudio se compara el esqueleto caudal de las especies A. lineatus y A. mazatlanus, con la finalidad de distinguir posibles diferencias entre ellas, tanto en formas juveniles como adultas.

\section{MATERIAL Y MÉTODO}

Los ejemplares de Achirus lineatus y A. mazatlanus, fueron obtenidos de la Colección Nacional de Peces del Instituto de Biología de la Universidad Nacional Autónoma de México (IBUNAM), así como de la Colección Ictiológica del Centro Interdisciplinario de Ciencias Marinas del Instituto Politécnico Nacional (CI-CICIMAR). Otros materiales fueron adquiridos de recolectas realizadas en la vertiente del Atlántico occidental: Puerto de Alvarado, Veracruz ( $18^{\circ}$ $46^{\prime} \mathrm{N}$ y $95^{\circ} 46^{\prime}$ W"), así como en la cuenca del Pacífico oriental tropical, a partir de recolectas realizadas en las inmediaciones del estero El Conchalito, ubicado en la Ense-

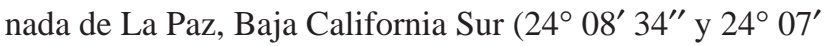
$40^{\prime \prime} \mathrm{N} ; 110^{\circ} 21^{\prime} 04^{\prime \prime} \mathrm{y} 110^{\circ} 20^{\prime} 35^{\prime \prime} \mathrm{W}$ ).

Las técnicas de aclarado (diafanización) y tinción diferencial de tejidos óseos y cartílago se hicieron de acuerdo con las metodologías descritas por Dingerkus \& Uhler (1977) y Potthoff (1984). Una vez transparentados, los esqueletos fueron examinados con ayuda de un microscopio estereoscópico LEICA S6E (Leica Microsystems AG), para elaborar los dibujos de las estructuras en diferentes tallas y llevar a cabo la descripción osteológica con base en el arreglo y nomenclatura de regiones anatómicas y estructuras del sistema esquelético caudal, propuestos por Hoshino (2001).

\section{RESULTADOS}

Se analizaron 50 esqueletos caudales, 25 de los cuales correspondieron a Achirus lineatus y 25 a A. mazatlanus. La estructura general del complejo caudal está compuesta por: 1 epural +5 hipurales +1 parahipural, una espina neural y dos espinas hemales; además de dos centros preurales.
Tales características fueron observadas tanto en organismos juveniles como adultos de ambas especies (en tallas de 18 a $180 \mathrm{~mm}$ LP; Figs. 1 y 2), por lo que se ofrece una descripción general para el esqueleto caudal.

Tanto en A. lineatus como A. mazatlanus, la espina hemal de la antepenúltima vértebra es de forma alargada y soporta el primer radio de la aleta caudal (Figs. 1 y 2); mientras que la espina neural de la antepenúltima vértebra, no se alarga de igual forma ni soporta radio alguno de la aleta caudal. Por otro lado, la espina hemal de la penúltima vértebra es larga y profundiza en el plano sagital formando parte del complejo caudal, donde soporta al segundo y parte del primer radio caudal. La espina neural, de esta penúltima vértebra, también forma parte del complejo caudal dando soporte al último radio.

En ambas especies, el hueso hipural 1 (HP1) se origina por debajo del primer centro preural (CPU1); además de que la parte distal de los hipurales dos al cuarto (HP2HP4), se origina desde los márgenes ventral y posterior del primer centro preural (CPU1), pero sin llegar a estar fusionados (con una clara separación de estos). Los hipurales se unen con ocho de los 16 radios de la aleta caudal; el hipural 5 (HP5) se localiza por encima de la última vértebra y está separado del centro preural. Los cinco hipurales presentan una forma triangular.

El parhipural que es de forma triangular, se encuentra adyacente a la espina hemal de la antepenúltima vértebra, su función es dar soporte al tercer, cuarto y parte del quinto radio caudal. El epural es más delgado en comparación con el grosor de los hipurales, se presenta adyacente a la espina neural de la penúltima vértebra y da soporte a los radios caudales 15 y 16 . El número total de radios en la aleta caudal es de 16 siendo notoria la ausencia de radios procurrentes.

En lo general, se establece que los organismos de las especies aquí estudiadas, mostraron un patrón similar en la estructura del esqueleto caudal. Sin embargo, se encontró que aquellos de A. mazatlanus (110 a $170 \mathrm{~mm}$ LP), presentaron una clara separación entre los hipurales, que difiere de la observada en A. lineatus (110 a $130 \mathrm{~mm} \mathrm{LP}$ ), donde estos huesos se pueden observar más cercanos unos de otros, pero sin estar fusionados.

\section{DISCUSIÓN}

El esqueleto caudal de los Pleuronectiformes ha sido descrito para diferentes especies, a partir de lo cual se han 


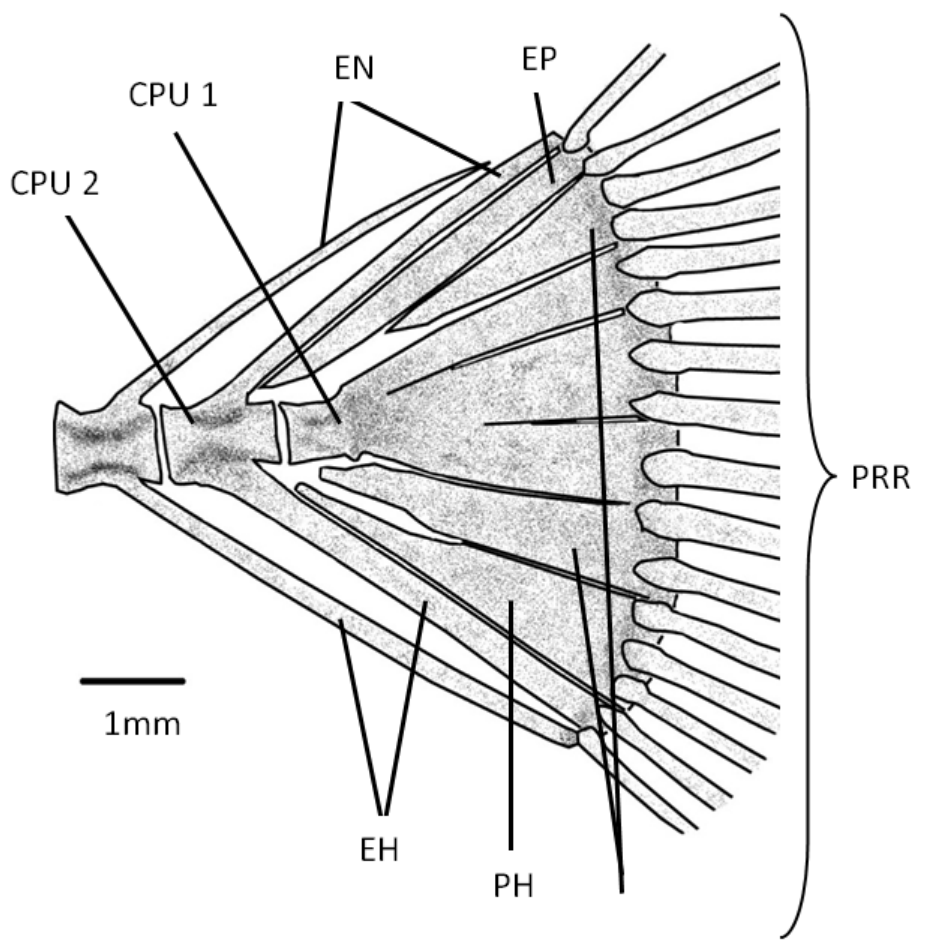

HP

Fig. 1. Esqueleto caudal de Achirus lineatus (Linnaeus, 1758), $40 \mathrm{~mm}$ LP. CNP-IBUNAM- 232. Estructuras observadas: epural (EP); hipural (HP); espina hemal (EH); espina neural (EN); parahipural (PH); radios principales (RP); centro preural 1 y 2 (CPU1, 2).

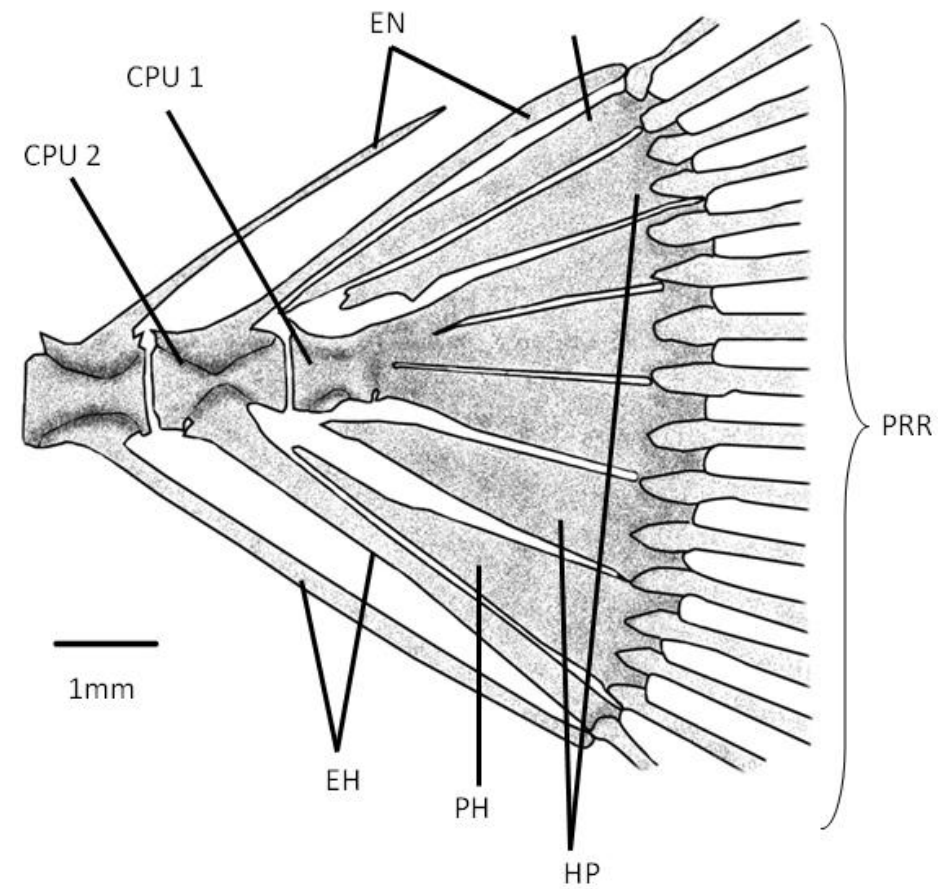

Fig. 2. Esqueleto caudal de Achirus mazatlanus (Steindachner, 1869), $36 \mathrm{~mm}$ LP. CNP-IBUNAM s/n. Estructuras observadas: epural (EP); hipural (HP); espina hemal (EH); espina neural $(\mathrm{EN})$; parahipural $(\mathrm{PH})$; radios principales (RP); centro preural 1 y 2 (CPU1, 2). establecido notables diferencias entre taxa superiores (e.g., Hoshino). Sin embargo, tal situación es contraria a lo que se pudo observar en el análisis del esqueleto caudal de las especies Achirus lineatus y A. mazatlanus, cuya estructura coincide en su composición general con la descrita para estos grupos: 1 epural +5 hipurales +1 parahipural, además de una espina neural, dos hemales y dos centros preurales. La fórmula caudal, número y tipo de elementos observados tanto en larvas como juveniles de A. lineatus, se corresponde con lo descrito por Futch et al. (1972) quienes hacen mención de la presencia de: 5 hipurales +1 epural +1 parahipural; además de una estructura y soporte similar de los radios caudales. Un esquema semejante también ha sido reportado por Hoshino para A. fasciatus (= Trinectes maculatus), sin embargo, esta especie difiere por la presencia de una curvatura al final del primer centro preural (CPU1). De la misma forma se coincide con lo reportado por Chapleau (1993), quien menciona como característica distintiva del género Achirus, la presencia de cinco placas hipúricas bien diferenciadas. En relación al número de elementos de la aleta caudal, las especies examinadas presentaron menos de 16 radios, característica que coincide con lo establecido por Futch et al. para A. lineatus y por Hoshino para el caso de A. fasciatus. Es posible pensar que la similitud encontrada en la fórmula y arreglo de la aleta caudal de las especies bajo estudio, sea un indicio de una relación evolutiva cercana entre ellas, lo que permite suponer que se trata de especies hermanas que evolucionaron a partir de un ancestro común, cuya población original pudo quedar aislada durante la última emersión del istmo centroamericano. Esta situación pudo dar origen a la formación de estas dos especies, a partir de un evento de especiación vicariante, razón por lo cual hasta ahora han sido consideradas como especies diferentes; aspecto que deberá ser corroborado mediante la realización de estudios filogenéticos ulteriores, que permitan confirmar este aserto.

Material Examinado: Achirus lineatus (Linnaeus, 1758). IBUNAM-P 11000, IBUNAM-P 11088, IBUNAM-P 603, IBUNAM-P 3112, IBUNAMP 232, IBUNAM-P 22075, IBUNAM-P 11114. A. mazatlanus (Steindachner, 1869) IBUNAM-P 1353, IBUNAM-P 1602 CICIMAR-CI 291, CICIMAR-CI 2838, CICIMAR-CI 296, CICIMAR-CI 1533. 


\section{AGRADECIMIENTOS}

Se agradece a H. Espinosa Pérez (CNP-IBUNAM) y personal de la CI-CICIMAR, las facilidades otorgadas para la revisión de ejemplares. JGN agradece al CONACyT y al Programa PIFI-IPN, los apoyos otorgados para la realización del presente estudio. AFGA, agradece al SNICONACyT, COFAA y EDI-IPN el soporte de la presente investigación.

GRACIAN-NEGRETE, J. M.; GONZÁLEZ-ACOSTA, A. F.; GONZÁLEZ-ISÁIS. M.; ORTIZ-GALINDO, J. L. \& DEL MORAL-FLORES, L. F. Comparative osteology of the caudal skeleton of Achirus lineatus and Achirus mazatlanus (Pleuronectiformes: Achiridae). Int. J. Morphol., 30(2):705-708, 2012.

SUMMARY: The caudal skeleton is recognized as an important source of information for establishment of teleostean interrelationships. A comparative analysis of the caudal skeleton of Achirus lineatus (Linnaeus, 1758) and A. mazatlanus (Steindachner, 1869) was performed, based on the examination of specimens from biological museums and others materials collected in Veracruz localities and Baja California Sur (Mexico). The specimens were identified using taxonomic keys and processed by means of clearing and staining methods, in order to determine the differences and similarities on the elements that characterized the caudal complex of this species. The caudal formula in A. lineatus and A. mazatlanus is composed by: 1 epural +5 hypurals +1 parhypural, one neural and two hemal spines, as well as the presence of 16 principal rays and absence of procurrent rays and the uroneural bone. The hypural in the $A$. lineatus are closer together; however, in general, differences were not observed among the species. Therefore, A. lineatus and A. mazatlanus are established as sister species.

KEY WORDS: Pleuronectiformes; Achiridae; Achirus; Caudal skeleton; Clearing and staining; Osteology

\section{REFERENCIAS BIBLIOGRÁFICAS}

Balart, E. F. Development of median and paired fin, skeleton of Paralichthys olivaceus (Pleuronectiformes: Paralichthyidae). Japan. J. lchthyol., 31(4):398-410, 1985.

Castro-Aguirre, J. L.; Espinosa-Pérez, H. S. \& Schimitter-Soto, J. J. Ictiofauna: Estuarino- Lagunar y Vicaria de México. México D.F., Noriega-Limusa, 1999.

Chapleau, F. Pleuronectiform relationships: A cladistic reassessment. Bull. Mar.Sci., 52(1):516-40, 1993.

Dingerkus, G. \& Uhler, L. D. Enzyme clearing of Alcian blue stained whole small vertebrates, for demostration of cartilage. Stain Techn., 5(4):229-32, 1977.

Eastman, J. T. The Caudal Skeletons of Catostomid Fishes. Am. Midl. Nat., 103(1):133-48, 1980.

Friedman, M. The evolutionary origin of flatfish asymmetry. Nature, 454(7201):209-12, 2008.

Futch, C. H.; Topp, L. W. \& Houde, E. D. Developmental osteology of the line sole (Pisces: Soleidae). Contrib. Mar. Sci., 16:33$56,1972$.

Gracian-Negrete, J. M. Osteología comparada de Achirus lineatus (Linnaeus, 1758) y Achirus mazatlanus (Steindachner, 1869) (Pleuronectiformes: Achiridae). Tesis Profesional. Facultad de Estudios Superiores Iztacala-Universidad Nacional Autónoma de México, 2009.

Gosline, W. A. The Perciform caudal skeleton. Copeia, 3:265-70, 1961.
Hilton E. J. \& Johnson, G. D. When two equals three: developmental osteology and homology of the caudal skeleton in carangid fishes (Perciformes: Carangidae). Evol. Dev., 9(2):178-89, 2007.

Hoshino, K. Homologies of caudal fin rays of Pleuronectiformes (Teleostei). Ichth. Res., 48:231-46, 2001.

Janvier, P. Squint of the fosil flatfish. Nature, 454(7201):169-70, 2008.

Ortiz-Galindo, J. L.; Matus-Nivón, E.; Ramírez-Sevilla, R. \& González-Acosta, B. Embrión, larva, y prejuvenil del sol mexicano Achirus mazatlanus (Pisces: Soleidae). Rev. Biol. Trop., 38(2A):195-204, 1990.

Potthoff, T. Clearing and staining techniques. In: Moser, H. G.; Richards, W. J.; Cohen, D. M.; Fahay, M. P. Kendall Jr. A. W. \& Richardson, S. L. (Eds.). Ontogeny and Systematics of Fishes. American Society of Ichthyologists and Herpetologists. Special publication No.1. Lawrence, KS, Allen Press, 1984.

Tucker, J. W. Larval development of Citharichthys cornutus, C. gymnorhinus, C. spilopterus, and Etropus crossotus (Bothidae), with notes on larval occurrence. Fish. Bull., 80:35-73, 1982.

Dirección para correspondencia:

González-Acosta Adrián Felipe

Centro Interdisciplinario de Ciencias Marinas- IPN.

Ave. Instituto Politécnico Nacional s/n.

Col. Playa Palo de Santa Rita.

La Paz, BCS

MÉXICO

Email: aacosta@ipn.mx

Recibido : 08-08-2011

Aceptado: 11-01-2012 